\title{
DUMPING E DIREITO INTERNACIONAL ECONÔMICO
}

\author{
Alice Rocha da Silva* \\ rochaalice@yahoo.com.br
}

RESUMO

Estamos na era da globalização, que tem por conseqüência o crescimento da concorrência, seja esta leal ou desleal. O dumping é considerado uma prática comercial desleal, sendo o Acordo Antidumping uma alternativa na defesa contra competições desleais no mercado internacional. Estes elementos constituem o objeto de estudo do presente trabalho, que primeiramente buscou tecer uma análise sob uma perspectiva teórica, sendo verificados pontos referentes a conceitos e modalidades de dumping, os quais serviram de base para a segunda etapa, quando se passou a analisar o Acordo Antidumping em si. Ao longo do trabalho são discutidos aspectos de ordem crítica, buscando ao final tecer considerações interpretativas dos dados, acrescidas de opiniões de ordem prática visando solucionar algumas das falhas verificadas, visto que a legislação antidumping não pode ser aplicada como barreira ao crescimento e desenvolvimento do comércio internacional, sendo necessário a correta identificação de práticas protecionistas e errôneas de sua aplicação.

Palavras-Chaves: Acordo Antidumping, concorrência, protecionismo.

\section{Dumping and Economic International Law}

\begin{abstract}
The world is now facing the globalization age that has, as its consequences, the growth of the competition, as it is loyal or not. Dumping is considered a disloyal practice, being the antidumping agreement, an alternative in defense against disloyal competitions in the international market. Those elements constitute the studying focus of this project, being verified aspects referred to general concepts and dumping modalities that would serve as a base for the second stage, when it starts to analyze the antidumping agreement itself. Along the project, it is discussed appreciation order aspects, seeking in the end, the creation of interpretative considerations of the data, adding practical order opinions that look for a solution of some of the failures verified, in as much as the antidumping legislation can not be applied as a barrier to the international market growth and development, at this necessary the right identification of the protectionists practices and mistakes of its application.
\end{abstract}

Keywords: Antidumping agreement, competition, protectionism

\footnotetext{
* Bacharel em Relações Internacionais, Ciências Políticas e Direito. Pesquisadora do Grupo integrado em Direito Internacional Econômico e Sistemas de Integração. Mestranda em Direito das Relações Internacionais do Programa de Mestrado em Direito do UniCEUB.
} 


\section{Introdução}

Este início do século XXI tem sido marcado pela tendência da busca da integração regional no aspecto econômico e conseqüente esforço para uma uniformização de normas internacionais que propiciem harmonia e paz entre os Estados. Exemplo disto seria a Comunidade Européia e o Mercosul. Assistimos à emergência de novos atores no cenário internacional, que colocam as Nações diante do importante desafio de exercer sua soberania de forma restrita devido aos compromissos firmados com as demais. Em relação ao comércio exterior, o aumento de fluxo de trocas e investimentos tem forçado os Estados a fortalecerem as regras de Direito Internacional, principalmente Econômico, almejando relações que primem pela justiça e lealdade.Este comércio internacional engloba a troca de mercadorias e serviços entre diferentes países, diferenciando-se do nacional, principalmente pelos encargos e barreiras aduaneiras.

O período pós Segunda Guerra Mundial foi o mais marcante no referente ao desenvolvimento do comércio internacional. Conseqüentemente, trouxe o advento de uma forte concorrência internacional acompanhada do aumento de práticas consideradas desleais por parte dos produtores. Uma destas práticas é o dumping, que vem a ser o lançamento de mercadorias em um mercado externo a preços abaixo do valor normal, executado em seu mercado, com o objetivo de prejudicar a concorrência tanto do país importador como dos demais produtores da mesma mercadoria ou similar a esta. ${ }^{1}$

O dumping se insere no contexto do direito da concorrência, visto que a legislação antidumping encontra respaldo neste ramo do direito, uma vez que busca impedir práticas que interferem no desenvolvimento de uma concorrência considerada "justa". Vale ressaltar que devido às mudanças que o mercado tem sofrido, como o fenômeno dos blocos de integração regional e a globalização, o conceito de concorrência perfeita, dado pelos clássicos, cedeu lugar à idéia de concorrência efetiva ou workable competition. Ou seja, não se trabalha mais com dogmas imutáveis, o que rege o estatuto do direito da concorrência seriam "regras do jogo", que têm por finalidade garantir a livre concorrência, admitindo, até

\footnotetext{
${ }^{1}$ Este conceito será mais bem explorado ao longo do texto. 
mesmo, intervenções no mercado que visem garantir a manutenção destas "regras".2 Paralelamente, vemos que as normas e instituições concorrenciais estariam regidas pela legislação interna de cada país, aplicada tanto a agentes públicos como privados, sendo um fato complicador no campo dos negócios jurídicos internacionais.

O regime de concorrência estaria diretamente subordinado ao Direito Econômico, o qual incide sobre as medidas de política econômica, adaptando-as aos objetivos defendidos pela Ordem Econômica e aos princípios ideológicos de uma democracia econômica e social. ${ }^{3}$ Podemos perceber que o regime jurídico da concorrência estaria ligado ao princípio da livre concorrência, tendo em vista que este é um princípio de suma importância para a harmonia da Ordem Econômica Mundial. Depreende-se então, que tal regime de concorrência seria totalmente contrário a práticas desleais de comércio, como o dumping, visto que propiciam distorções no mercado mundial, e conseqüente deturpação do princípio da livre concorrência.

Diante do exposto, nos propomos a tratar o dumping começando por sua conceituação e evolução até a análise do Acordo Antidumping, utilizando-se de casos concretos que venham demonstrar a relevância do fenômeno no campo do Direito Internacional Econômico.

\section{Conceito de dumping}

Considerando-se dumping como forma de concorrência desleal podemos caracterizá-lo sob dois aspectos: sob o âmbito interno, seria definido como a venda injustificada de mercadoria abaixo do preço de custo ${ }^{4}$ e sob o âmbito internacional, seria entendido como a venda de produtos ao exterior a preços abaixo do valor normal praticado no mercado interno. ${ }^{5}$ Todavia, a acepção mais corrente e, portanto considerada neste momento será a de dumping no contexto internacional. Vale ressaltar que alguns equívocos devem ser evitados, como a confusão entre dumping e "underselling" e entre dumping e

\footnotetext{
${ }^{2}$ SILVEIRA, Paulo Antônio Caliendo Velloso da. Defesa da concorrência no Mercosul: acordos entre empresas, abuso de posição dominante e concentrações. São Paulo: LTr, 1998, p. 56-57.

${ }^{3}$ VAZ Isabel. Direito econômico da concorrência. Rio de Janeiro: Forense, 1993, p. 264.

${ }^{4}$ Vide artigo 21, XVIII, Lei 8.884/94. Vale salientarmos que há autores que consideram a prática de dumping como a ocorrência de preços abaixo do custo de produção, inclusive no mercado internacional. Ver HOEKMAN, Bernard M.; KOSTECKI, Michel M. The political economy of the world trading system: the WTO and beyond. 2 ed. Oxford University Press, 2001, p. 315.

${ }^{5}$ RATTI, Bruno. Comércio internacional e câmbio. 10. Ed. São Paulo: Aduaneiras, 2001, p. 399.
} 
preço predatório. $\mathrm{O}$ underselling seria a venda de um produto a um preço abaixo do custo de produção do mesmo, característica não necessária para a configuração da prática do dumping, visto que neste o produto é vendido abaixo do preço praticado no mercado interno do exportador. Já em relação à preço predatório, este consiste na venda abaixo do preço normal com intenção clara de eliminação da concorrência, enquanto que o dumping só possuiria esta característica se fosse considerado condenável.

Dumping é um termo que muitas vezes é utilizado de forma errônea por envolver conotações variadas. Na busca por uma definição do mesmo, autores fazem uso de diversas metodologias. Existe uma conceituação que é bastante interessante por se valer de argumentos que justificam a aplicação de medidas impeditivas da prática do dumping. Segundo esta linha, o conceito de dumping estaria dividido em três acepções: jurídico, econômico e político. ${ }^{6}$

A jurídica seria aquela definida no próprio Acordo Antidumping, o qual prevê a prática de dumping quando da "oferta de um produto no comércio de outro país a preço inferior a seu valor normal, no caso de o preço de exportação do produto ser inferior àquele praticado, no curso normal das atividades comerciais, para o mesmo produto quando destinado ao consumo no país exportador". ${ }^{7}$ Esta acepção é bastante criticada pela falta de clareza de alguns dos seus elementos, além de não levar em consideração a complexidade das realidades que envolvem o fenômeno.

A abordagem econômica distancia-se um pouco da jurídica, considerando questionáveis os fundamentos de aplicação das medidas, ao passo que na jurídica eles estão objetivados pela norma. Em linhas gerais, o fundamento econômico seria de que as medidas antidumping são necessárias para a proteção da indústria nacional, frente a uma concorrência estrangeira desleal. Nesta concepção o dumping seria nocivo à indústria nacional por ser uma manifestação de preços predatórios. ${ }^{8}$

Por fim teríamos a acepção política, a qual é bastante interessante por ser uma tentativa de explicar a persistência da legislação antidumping mesmo sendo permeada por

\footnotetext{
${ }^{6}$ BARRAL, Welber. Dumping e comércio internacional: a regulamentação antidumping após a Rodada Uruguai. Rio de Janeiro: Forense, 2000, p. 16-71.

${ }^{7}$ Vide art. II, 1.

${ }^{8}$ Situação em que primeiramente os preços são reduzidos, visando a conquista do mercado nacional, para em seguida serem aumentados, propiciando a recuperação dos lucros.
} 
fortes críticas. Politicamente, explica-se a legislação antidumping como uma medida de política jurídica ${ }^{9}$, um meio termo entre liberalização econômica e proteção do mercado nacional e como meio de retaliação estatal no plano internacional.

Tais fundamentações são bastante criticadas por serem dependentes de variáveis instáveis e por não conseguirem envolver a realidade sócio-econômica dos Estados de forma uniforme. Sendo assim, a formulação de uma assertiva generalizante seria uma pretensão no mínimo comprometida. Tais variáveis vão depender da capacidade de organização da sociedade e de seus decorrentes grupos de pressão, da importância do comércio internacional para o país e das parcelas do comércio internacional pertencentes a cada país.

Há ainda outras definições na doutrina. Todavia, condições comuns a todas elas para a caracterização do dumping como prática desleal de comércio seria a introdução de um bem no mercado doméstico a preço de exportação inferior ao valor normal, o dano à indústria doméstica e o nexo causal entre a prática de dumping e o dano sofrido. ${ }^{10}$ Sendo assim, podemos definir a natureza do dumping como um ilícito jurídico-econômico, por ser um fato regulado por leis e tratados que prevêem sanções, além de ser um ato que busca a aquisição de vantagens econômicas de forma injusta. ${ }^{11}$

\section{Antidumping, Antitrust e Subsídios: Diferentes Instrumentos}

Importante neste ponto é marcarmos a diferença entre dumping e trust em um primeiro momento e de dumping e subsídios em seguida. Estes são institutos bastante confundidos por operadores jurídicos de Direito Internacional Econômico, mas que tecnicamente apresentam diversas distinções e que serão brevemente abordadas. Analisando a diferença entre a legislação antidumping ou defesa comercial e a legislação antitrust ou proteção da concorrência efetiva, percebemos que ambas tratam da proteção da

\footnotetext{
${ }^{9}$ Práticas jurídicas destinadas à autonomia social e individual.

${ }^{10}$ GOYOS JUNIOR, Durval de Noronha [et al.] Tratado de defesa comercial: antidumping, compensatórias e salvaguardas. São Paulo: Observador Legal, 2003, p. 6.

${ }^{11}$ MARQUES, Frederico do Valle Magalhães. O "Dumping" na Organização Mundial do Comércio e no Direito Brasileiro - Decreto n. 1.602/95. In: CASELLA, Paulo Borba; MERCADANTE, Araminta de Azevedo. (coord.) Guerra comercial ou integração mundial pelo comércio?: a OMC e o Brasil. São Paulo: LTr, 1998, p. 299.
} 
concorrência entre agentes econômicos, entretanto, os casos em que cada uma se encaixa são diferentes. Uma primeira diferença seria quanto aos sujeitos das práticas comerciais. Enquanto no dumping a relação se dá entre empresas de Estados diferentes ou entre empresa nacional e outro Estado, na proteção da concorrência efetiva são empresas de um mesmo mercado ou de um mercado comum que estão relacionadas na prática desleal. Temos também uma diferenciação quanto ao objeto ou tipo de operação comercial realizada. No dumping o que ocorre são exportações de bens abaixo do preço praticado no mercado do país exportador, enquanto que o trust abrange, além da negociação de mercadorias, os serviços. A legislação antitrust busca permitir aos agentes nacionais uma concorrência justa entre eles. $^{12}$

Dumping e subsídios são dois temas previstos em Acordos distintos (Acordo Antidumping e Acordo sobre Subsídios e Medidas Compensatórias), estando ambos dispostos na Ata final da Rodada Uruguai, assinada em Marraqueche. Razões técnicas não existem para que os temas sejam confundidos, visto que têm natureza jurídica diferente, com critérios de apuração também distintos. Dumping trata essencialmente da prática de preços discriminatórios em diferentes mercados nacionais, subsídios, por sua vez, seriam contribuições financeiras ao exportador estrangeiro, que o governo ou órgãos públicos dão, seja na forma de transferência direta de fundos, perdão de dívidas públicas ou fornecimento de bens e serviços além do necessário para infra-estrutura em geral. ${ }^{13}$

Em comum, os dois institutos objetivam em suas investigações a imposição de tarifas antidumping e de direitos compensatórios buscando remediar, e não punir, preços desleais de mercadoria importada, visto que se cobra apenas o necessário para neutralizar a margem de dumping (diferença de preço no país importador comparado ao país exportador) ou o valor do subsídio (o montante do benefício econômico conferido ao exportador estrangeiro pelo subsídio). Em geral, as medidas antidumping e de direitos compensatórios são impostas para o futuro, salvo exceções em que se permite a aplicação retroativa das tarifas. $^{14}$

\footnotetext{
${ }^{12}$ Este é o caso da legislação comunitária européia a respeito da proteção da concorrência que envolve serviços de profissionais liberais, seguros e proteção agrícola, com algumas exceções. Ver SILVEIRA, op. Cit. p.26.

${ }^{13}$ Ver Decreto ${ }^{\circ} 1.751 / 95$, dispositivo legal que trata do tema no Brasil.

${ }^{14}$ Vide www.kslaw.com
} 
Certos autores ${ }^{15}$ defendem inclusive que práticas comerciais subsidiadas por governos são mais perigosas para os países importadores do que o dumping em si. Argumentam que o governo teria mais força do que as empresas privadas para sustentar uma prática anticoncorrencial por meio de preços subsidiados. Conseqüentemente, o dano material causado à indústria doméstica do país importador também é maior quando se trata da presença de subsídios governamentais, e, portanto, tal prática deve ganhar maior atenção.

\section{Evolução e Importância das normas antidumping no Direito Internacional}

\section{Econômico}

Mecanismos de defesa de mercados contra práticas desleais de comércio não são recentes. Todavia, a aplicação que é dada a estes mecanismos tem se modificado ao longo dos anos, visto que o comércio internacional sempre foi bastante dinâmico e a concorrência entre os mercados cada vez mais acirrada. Entre os estudiosos do assunto, sempre houve uma falta de consenso a respeito da utilização do termo, até a formulação de um conceito operacional comum. ${ }^{16}$

Um dos primeiros Estados a definirem um conceito legal e a utilizararem regras referentes a dumping foi o Canadá em 1904. Seus dispositivos já mencionavam a imposição de direitos antidumping equivalentes à diferença entre o preço exercido no Canadá e o preço no país que estava exportando. Neste momento, havia uma evidência de que tal regulação não passava de um ato protecionista por parte do governo canadense, que não questionava a intenção do exportador, nem um dano real da indústria canadense em relação

\footnotetext{
${ }^{15}$ HARTIGAN, James C.; KAMMA, Sreenivas; PERRY, Phillip R. Are subsidies more dangerous than dumping? Journal of Economic Integration, Korea, v. 9, n. 1, p. 1-28, 1994. In: JOHANNPETER, Guilherme Chagas Gerdau. Antidumping: prática desleal no comércio internacional. Porto Alegre: Livraria do Advogado, 1996.

${ }^{16}$ Adam Smith já fazia uso do dumping para fazer menção à interferência do Estado na economia em situação de auxílios econômicos aos produtores, o que hoje se assemelha ao que denominamos subsídios. Há ainda, registros de discussões a respeito do termo, em debates do Congresso dos EUA em 1884, fazendo-se referência aos bens estrangeiros vendidos em território norte-americano (BARRAL, op. cit., p. 10). Também se menciona que já no século XVI, industriais ingleses reclamavam da entrada de papel a preços prejudiciais à indústria de celulose que nascia na Inglaterra. Entretanto, somente anos mais tarde é que se publicou a obra Dumping, a problem in international trade (VINER, 1966, p. 4-5), delimitando os traços que caracterizariam a prática do dumping, atribuindo a ele a essencial discriminação de preços entre compradores de diferentes mercados nacionais.
} 
àquela importação. Outros países seguiram esta mesma linha como a Austrália, o Reino Unido e os Estados Unidos.

Nos Estados Unidos, a legislação antidumping nasceu com o Antidumping Act (Revenue Act), em 1916. Este já demonstrou certa evolução por considerar crime a prática que fosse proveniente de um exportador comprovadamente intencionado a causar danos aos concorrentes nacionais. ${ }^{17}$ Tais dispositivos formavam uma extensão da legislação Antitruste e foram bastante utilizados como medida protecionista unilateral. Em 1921, este Estatuto Antidumping de 1916 foi alterado (US Antidumping Act), trazendo como inovação à apuração de direitos antidumping com um caráter mais administrativo do que jurídico e o esclarecimento de alguns termos como "dano à indústria". ${ }^{18}$

A legislação antidumping foi aprovada com a finalidade de ser o principal instrumento de regulação de importações, mas ela não começou a ser utilizada de forma imediata. Como exemplo disto, podemos mencionar que nos Estados Unidos as tarifas continuaram a ser o instrumento de proteção predominante. ${ }^{19}$ A implementação da legislação variou de país para país, de acordo com as peculiaridades de cada um. ${ }^{20}$

Dados relativos à aplicação da legislação antidumping demonstram a evolução do fenômeno e a importância que vem adquirindo com o passar dos anos. Muitas ações são iniciadas e não foram efetivamente concluídas com imposição de medidas antidumping. Devemos nos questionar o porquê de um número tão alto de investigações iniciadas e menos da metade destas (na maioria dos anos) concluídas com imposição de medidas antidumping.

Uma primeira hipótese que poderíamos mencionar seria a não implementação das imposições por uma questão de constrangimento político, que pode ocorrer em situações de aliança e compromissos assumidos (como compromisso de cooperação, por exemplo) pelos países envolvidos, onde se verifica uma preferência por deixar de impor tais medidas do

\footnotetext{
${ }^{17}$ A penalidade poderia consistir em multas de até US\$ 5000,00 ou prisão de até um ano. (GUEDES, Josefina Maria M. M. Anti-dumping, subsídios e medidas compensatórias. 3 ed. São Paulo: Aduaneiras, 2002, p.29.

${ }^{18}$ GOYOS JUNIOR, op. cit., p.11.

${ }^{19}$ No caso WT/DS 136, a União Européia entrou com painel alegando a incongruência entre as normas da OMC e a legislação interna dos EUA concernente ao Ato de 1916. O painel decidiu pela inconsistência do Ato com o Artigo VI do GATT (Acordo Antidumping), recomendando a adequação do Ato às obrigações constantes nos Acordos da OMC.

${ }^{20}$ JOHANNPETER, op. cit. , p. 60. 
que criar uma indisposição com o aliado. Exemplo disto seria o caso bananas na OMC, no ano de 1996, que envolveu Equador, Guatemala, Honduras e México, contestando o novo regime da Comunidade Européia relativo à importação e exportação de bananas. ${ }^{21}$

Devemos assinalar também que existem fatores que incentivam a iniciação de ações antidumping, mesmo que as mesmas não sejam impostas. Um deles seria a permissibilidade da prática de ações discriminatórias sem a necessidade de renegociação ou compensação. Seus requisitos são mais facilmente demonstráveis que aqueles exigidos para as ações emergenciais. $^{22}$

Várias conseqüências podem advir da imposição de direitos antidumping provisórios ou definitivos, os quais acabam se prolongando e afetando até mesmo negócios futuros das empresas. Os doutrinadores norte-americanos dão o nome de harassment effect ou "efeito causador de dano". Até mesmo o início de uma investigação de dumping já pode acarretar tal efeito, por afetar sua imagem perante seus clientes reduzindo as importações. Nos Estados Unidos, verifica-se que em muitos casos as empresas que praticam o dumping preferem cessar tal prática, a enfrentar as repercussões de uma investigação. Atualmente, não existem jurisprudências no sentido de existirem indenizações em razão de prejuízos decorrentes do "efeito causador de dano", para os casos em que fique provado que a prática de dumping não existia, visto que existe a possibilidade de negócios terem sido interrompidos ou cancelados durante o período de investigação. ${ }^{23}$

Com a criação da Organização Mundial do Comércio, assistiu-se a um uso mais intensivo das medidas antidumping. Uma das razões foi a proibição da utilização das restrições voluntárias de exportações, por terem sido contrárias aos propósitos gerais da nascente Organização. Os países em desenvolvimento também passaram a utilizar tais medidas de forma mais intensa, podendo ser citado como exemplo o fato de que em 1999, na relação de países que mais utilizavam as ações antidumping encontra-se Argentina, Brasil, Índia e África do Sul. ${ }^{24}$ Dados da Organização Mundial do Comércio demonstram

\footnotetext{
${ }^{21}$ HOEKMAN e KOSTECKI, op. cit., p. 80. (WT/DS27)

${ }^{22}$ KRUEGER, Anne O. (ed.) The WTO as na international organization. The University of Chicago Press, 2000, p.377-8.

${ }^{23}$ JOHANNPETER, op. cit.

${ }^{24}$ HOEKMAN e KOSTECKI, op. cit., p. 316. 
que, entre 1995 e o primeiro semestre de 2003, a Argentina havia imposto 138 medidas, enquanto que a Comunidade Européia 184 e os Estados Unidos 196.

Além disso, dados demonstram a incidência muito alta de ações antidumping sobre produtos que, normalmente, são utilizados como insumo para a produção de bens de consumo, como por exemplo, os metais de base e derivados, que representam $38,0 \%$ do total de medidas em 2001, como também os produtos químicos e derivados, que responderam por $17,0 \%$ do total de medidas no mesmo período. ${ }^{25}$

Este é um ponto que merece ser analisado, pois demonstra uma realidade que talvez não tenha passado em nossa mente, uma vez que tendemos muito mais a crer que os produtos com maior incidência de ações antidumping seriam bens finais para o consumidor. A importação de insumos a preço de dumping afetaria todas as empresas do país, tanto as que produzem insumo quanto as que os utilizam no processo de fabricação de seus bens. Estes dados também merecem atenção por demonstrarem que se trata de negociações entre empresas ou pessoas associadas ${ }^{26}$, visto que o produto importado não será destinado diretamente à revenda, mas sim submetido a algum processo de industrialização.

Por fim, podemos deduzir um caráter protecionista da legislação antidumping, sobretudo em se tratando de determinados produtos político-economicamente importantes para alguns países, como setores industriais com problemas de competitividade, como o setor de metais de base e derivados. A prática norte-americana tem demonstrado que em função de interesses políticos, tem-se aplicado medidas anti-dumping contra produtores estrangeiros. A Organização Mundial do Comércio já foi provocada sobre o tema, regularizando tais distorções.

\section{Evolução quanto às modalidades de dumping}

A evolução dos estudos do fenômeno dumping trouxe a tona a definição de modalidades ou de formas para avaliá-lo, partindo da premissa de que existiriam diversas motivações para tal prática e, portanto, não poderia ser considerado como algo único. ${ }^{27}$ Esta

\footnotetext{
${ }^{25}$ World Trade Organization. Annual Report 2003. WTO: Geneva, 2003. p. 24.

${ }^{26}$ Possivelmente se trata de empresas multinacionais ou transnacionais.

${ }^{27}$ JOHANNPETER, op. cit., p. 83-88.
} 
categorização seria uma tentativa de ampliação do conceito, sendo que decorre muito mais de fatores econômicos do que jurídicos, afinal, a análise jurídica se dá somente após a constatação da prática de dumping mediante investigação de caráter econômico. Deste modo, são modalidades de dumping: por excedente, predatório, tecnológico, estrutural, social ecológico e cambial.

a) Dumping por excedente: caracterizado pela busca da maximização de vendas ao invés de lucros, é possível pela dissolução dos custos fixos causados por um aumento na produção, trazendo como conseqüência ganhos em economia de escala. O excesso de produção seria direcionado para a exportação, causando um aumento da oferta do produto e a conseqüente retração do preço deste no país importador.

b) Dumping predatório: este tipo se enquadraria na chamada competição predadora, em que se busca a eliminação da concorrência que fabrica produto similar. Seria semelhante ao que ocorre no mercado interno, onde o fabricante vende, durante um período, a preço abaixo do custo de produção, com a pretensão de acabar com a concorrência e em um segundo momento, quando já estiver em posição privilegiada, subir os preços e lucrar acima do normal. Esta seria a única modalidade condenável.

c) Dumping tecnológico: esta modalidade aparece na situação em que a tecnologia muda tão rapidamente que o custo de produção vai ficando cada vez mais baixo, sendo constatado pela curva de aprendizado (learning curve) ${ }^{28}$ e culminando em um dumping estratégico.

d) Dumping estrutural: ocorre quando o mercado tem um excesso de oferta de produto, o que motiva a exportação a preços mais baixos que os praticados no mercado interno. Os setores mais problemáticos neste aspecto seriam o petroquímico e o siderúrgico. Vale salientarmos que a legislação não prevê em seus dispositivos a necessidade da análise da estrutura do mercado em questão.

e) Dumping social: as diferenças sociais entre os países-membros, como remuneração e direitos trabalhistas, são consideradas causas que contribuem bastante para a prática do dumping social. O custo final do produto é bastante influenciado pelo custo da mão-de-obra, encontrando-se neste aspecto uma vantagem comparativa para os países em

\footnotetext{
${ }^{28}$ Demonstrativo das reduções de custo alcançadas por uma empresa em um determinado espaço de tempo.
} 
desenvolvimento em relação aos economicamente desenvolvidos, por terem maior oferta de pessoal. Todavia, esta vantagem pode ser compensada pela maior produtividade dos países em desenvolvimento. Salários e condições de trabalho variam muito de país para país, logo, uma uniformização disto no âmbito da OMC seria praticamente impossível. Apesar da sua importância, o tema não deve ser objeto de análise pelo OMC e sim da Organização Internacional do Trabalho (OIT), que trata, entre outras coisas, da equalização da relação capital-trabalho entre os Estados. A tentativa de caracterização do dumping social é vista pelos países em desenvolvimento como meio de justificar práticas protecionistas aos seus produtos.

f) Dumping ecológico: também chamado de ambiental, esta modalidade é bastante utilizada pelos europeus sendo caracterizada pela utilização de material nãoreciclável, proveniente de fontes naturais não-renováveis. Pode ainda se manifestar quando da transferência de empresas que são consideradas poluentes em um determinado país, para outro local onde as exigências de proteção ao meio-ambiente sejam menores, acarretando em menores gastos destinados à proteção ambiental. Neste campo específico, podemos verificar sanções justificadas por um protecionismo disfarçado, que ignora o fato de países utilizarem material plantando exclusivamente para uso industrial, e aplicam medidas que prejudicam o livre comércio e constituem verdadeiras barreiras a países exportadores e concorrentes.

g) Dumping cambial: seria constatado no momento em que os governos nacionais praticam uma manutenção artificial de taxas de câmbio abaixo do que realmente são. Isto reforçaria os preços de exportação e em contra partida acabariam por "proibir" as importações. Esta situação é facilitada pela ausência de um sistema de compensação internacional de câmbios monetários, que traz como conseqüência uma falta de base real de equiparação de moedas nacionais, possibilitando desvalorizações ou supervalorizações de acordo com o interesse do governo ou de especuladores privados.

Estas são categorizações feitas no campo teórico. Para a aplicação da legislação antidumping não existe uma distinção de tipos de dumping. A única diferenciação mencionada seria entre dumping condenável ou não-condenável, de acordo com a 
ocorrência ou não de danos negativos para a indústria do país importador, devendo ser comprovado também o nexo causal.

\section{A construção de normas no âmbito da Organização Mundial do Comércio}

\subsection{Origem e regulamentação}

Atualmente, o Entendimento na implementação do artigo VI do GATT 1994, que faz parte do Acordo de criação da Organização Mundial do Comércio (OMC), é considerado o parâmetro na questão da legislação antidumping. Negociações multilaterais formaram a base deste Entendimento, que foi objeto de discussão desde o GATT/1947. ${ }^{29}$ Todavia, foi somente na Rodada Tóquio (1973-1979) que o instituto veio a se tornar assunto na pauta de discussão do Organismo.

Na Rodada Tóquio, entre outros temas como subsídios e medidas compensatórias, foram revistos os dispositivos do Código Antidumping criado na Rodada Kennedy, em 1967. Esta revisão alterou o conceito de causalidade, mas a legislação antidumping continuou a ser bastante criticada por seu uso como instrumento de "políticas econômicas protecionistas". Este Código de 1979 ainda deixou algumas ambigüidades, o que já antecipava a necessária revisão do Código na rodada seguinte que seria a do Uruguai. ${ }^{30}$

Na Rodada Uruguai (1986-1994), vários pontos do acordo foram revistos na busca de maior clareza e eficácia aos dispositivos da legislação antidumping, o que proporcionaria maior segurança jurídica aos parceiros comerciais. Nesta ocasião ficou definido que as medidas antidumping só poderiam ser aplicadas nos casos previstos no Artigo VI do GATT $1994^{31}$, seguindo as investigações iniciadas e conduzidas de acordo com o Acordo Antidumping. Um dos temas mais polêmicos e discutidos na Rodada Uruguai foi o Órgão de solução de Controvérsias, visto que este adquiriu uma importância

\footnotetext{
${ }^{29}$ BARROS, Maria Carolina Mendonça de. Antidumping e protecionismo. São Paulo: Aduaneiras, 2003, p. 15.

${ }^{30}$ BARRAL, op. cit., p. 84.

${ }^{31}$ O GATT 1994 representa o Anexo I do Acordo Constitutivo da OMC e pouco mudou em relação ao GATT 1947.
} 
cada vez maior ao longo dos anos, tendo uma influência direta sobre os interesses dos países membros. $^{32}$

Dentre os resultados da Rodada Uruguai, um dos mais importantes foi a criação da Organização Mundial do Comércio, que passou a existir a partir de $1^{\circ}$ de janeiro de $1995^{33}$. Não se pode dizer que entre a OMC e o GATT ocorreu uma ruptura, pois se trata de um mesmo processo de evolução do direito internacional econômico. O tratado constitutivo da OMC em seu artigo 16 prevê que as práticas e decisões no âmbito do GATT servem de guia para a nova Organização. ${ }^{34}$

As duas últimas Rodadas (Uruguai e Doha), trouxeram importantes modificações no Código Antidumping, vale ressaltar que o posicionamento dos Estados Unidos sempre foi o de resistência a estas mudanças. A questão já vinha sendo discutida desde a tentativa de lançamento da Rodada do Milênio, quando o grupo dos $33^{35}$, denominado "amigos do dumping", buscava revisar alguns dispositivos e coibir certos abusos apresentando mais de 20 sugestões de reforma. As sugestões visavam, entre outras metas, conferir uma maior transparência aos processos e maior grau de tecnicidade às decisões.

\section{2. Órgão de Solução de Controvérsias (OSC)}

O OSC tem por função julgar os litígios entre os países-membros, entre eles os casos que envolvem dumping, situações em que se aplica o acordo antidumping. ${ }^{36} \mathrm{~A}$ adoção do OSC que possibilitaria a aplicação de retaliações aos membros que infringissem regras da OMC, foi um dos mais importantes resultados da Rodada Uruguai. Este novo

\footnotetext{
${ }^{32}$ GUEDES, op. cit., p. 39.

${ }^{33}$ A OMC foi criada em 15 de abril de 1994, por meio dos Acordos de Marraqueche, entrando em vigor em $1^{\circ}$ de janeiro de 1995. A Organização está sediada em Genebra, Suíça. Seu Acordo constitutivo compreende quatro Anexos: Anexo I que se subdivide em a) Acordos Multilaterais de Comércio de Bens (GATT - General Agreement on Trade and Tariffs); b) Acordo Geral sobre o Comércio de Serviço (GATS - General Agreement on Trade in Services); c)Acordo sobre Aspectos dos Direitos de Propriedade Intelectual Relacionados ao Comércio (TRIPS - Trade Related Aspects of Intellectual Property Rights). Anexo II que se relaciona às Normas e Procedimentos sobre Resolução de Controvérsias. Anexo III, o qual diz respeito aos Mecanismos de Exame de Políticas Comerciais. Anexo IV referente aos Acordos de Comércio Plurilaterais. O Acordo Antidumping se insere no anexo I a).

${ }^{34}$ PRAZERES, Tatiana Lacerda. Comércio internacional e protecionismo: as barreiras técnicas na OMC. São Paulo: Aduaneiras, 2003, p.33.

${ }^{35}$ Este grupo era formado por Brasil, Chile, Colômbia, Coréia, Costa Rica, Hong-Kong, Israel, Japão, México, Noruega, Singapura, Suíça, Tailândia e Turquia. V. GOYOS JUNIOR, op. cit., p. 16.

${ }^{36}$ Acordo sobre a implementação do artigo VI do Acordo Geral sobre Tarifas e Comércio 1994.
} 
sistema era muito diferente do adotado no âmbito do GATT. Uma das principais diferenças é que no GATT, o país-membro que se sentisse lesado por alguma decisão poderia bloquear a decisão, o que abalava a legitimidade do sistema. ${ }^{37} \mathrm{O}$ Acordo da OMC por sua vez, trouxe o consenso negativo ${ }^{38}$, tornando-se mais forte. A OMC tinha em suas mãos a poder de impor as decisões dos painéis e permitir a aplicação de retaliações no caso do perdedor manter medidas incompatíveis com as regras da Organização. Comparativamente ao sistema vigente no GATT, podemos dizer que houve um aumento do caráter jurídico em detrimento da faceta diplomática ou política, entretanto, os acordos diplomáticos parte da antiga importância.

O Acordo da OMC também trouxe o estabelecimento de um Órgão de Apelação ou Tribunal de Apelação, com a finalidade de verificar os fundamentos legais do relatório do painel e das suas conclusões. Existe também um conjunto de regras denominado "Entendimento Relativo às Normas e Procedimentos sobre Solução de Controvérsias" (Understanding on the Rules and Procedures Governing the Settlement of Disputes, também conhecido como Dispute Settlement Understanding - DSU), que deve ser combinado com as regras dos acordos negociados, prevalecendo as últimas em relação às primeiras.O artigo de Luis Claudio Coni, publicado também neste volume, analisa de forma mais aprofundada a questão. ${ }^{39}$

Vale salientarmos que o OSC não tem a função de punir os membros que adotassem práticas incompatíveis e sim reforçar a observância das regras comerciais multilaterais e a adoção de práticas compatíveis com os acordos negociados. A qualquer momento, o conflito pode ser solucionado e o caso encerrado por meio de um acordo entre as partes envolvidas no contencioso. Apesar do procedimento adotado dentro do OSC ser

\footnotetext{
${ }^{37}$ No GATT havia a previsão de em casos de conflitos, ocorreria um processo de consultas e depois o estabelecimento de painéis de especialistas, que elaboravam um relatório. Este relatório teria que ser aprovado por consenso pelo Conselho Geral. Desta forma, para que o processo fosse bloqueado bastava à parte perdedora não aceitar o relatório. Para maiores detalhes ver HOEKMAN Bernard; MATTOO, Aaditya; ENGLISH, Philip (ed.) Development, trade, and the WTO: a handbook.. Washington: BIRD, 2002, p.77.

${ }^{38}$ Consenso negativo significa que para que um relatório fosse derrubado deveria haver um consenso. Além disso, o número de recursos no sistema do OMC é reduzido em relação ao do GATT, pois os casos não são levados aos Comitês.

${ }^{39}$ JOHANNPETER, op. cit., p. 51.
} 
simplificado e ágil ${ }^{40}$, as partes também podem optar pelo método alternativo da arbitragem, do qual resultará um acordo entre as partes litigantes.

Mais uma vez deve-se frisar que o sistema de solução de controvérsias não se limita somente à etapa de retaliação, tendo também um caráter negocial na solução de disputas. Muitos casos submetidos ao OSC já eram discutidos antes mesmo da apresentação formal de um pedido de consultas. Vale notar, que mesmo as negociações se operando somente entre os litigantes, todos os membros da OMC se aproveitam delas, em função da cláusula da nação mais favorecida.

\subsection{Do Acordo Antidumping}

\section{a) A verificação da necessidade de medidas antidumping}

Nem toda venda abaixo do preço de custo constitui uma prática desleal ao comércio. O julgamento disto se dará, tendo em vista a forma que o governo pode reagir ou não ao dumping, isto sim disciplinará as medidas antidumping. Ou seja, para aplicação de direitos antidumping, o nexo de causalidade deve estar bem definido e a medida deve ser realmente necessária. Mas como definir o quando uma medida é realmente necessária? Fatores sociais e culturais interferem nesta determinação, tais como organização social, por exemplo. Ademais, antes da aplicação efetiva de uma medida antidumping, é importante haver um processo de negociação, com o objetivo de se chegar a medidas alternativas. Depreende-se, portanto, que o conceito de medida necessária ainda é muito dúbio, existindo junto com ele outros conceitos bastante questionáveis também. Como por exemplo, discriminação arbitrária, injustificável, recursos naturais esgotáveis, entre tantos outros.

\footnotetext{
${ }^{40} \mathrm{O}$ primeiro passo são as consultas entre os países litigantes, ocasião em que se busca um acordo entre eles. Caso não se obtenha resultados, a parte demandante pode solicitar o estabelecimento de um painel. Geralmente, o painel elabora seu relatório no prazo de seis a nove meses, podendo variar de acordo com a dinâmica do processo negociador e da natureza da questão envolvida. Os relatórios são distribuídos às partes e depois passam para apreciação e adoção pelo OSC. Pode ainda haver apelação interposta ante o Órgão de Apelação (AO). O OSC adota o relatório do Painel ou do OA, chamando o membro a informar quanto às suas intenções no sentido de implementar as decisões e recomendações estabelecidas pelo OSC. Caso não haja implemento no prazo acordado, pode haver negociações de compensações satisfatórias ou ainda suspender a aplicação de concessões ou retaliação. Para a definição da maneira e valor que versará a suspensão da aplicação de concessões faz-se uso de técnicas da arbitragem dentro de um comitê de arbitragem. Após esta determinação, a parte interessada deve solicitar autorização ao OSC para só então poder aplicar tal suspensão.
} 


\section{b) Caracterização do dumping}

Como regra geral, o dumping ocorre em casos em que um produto é ofertado no comércio de outro país, a um preço (preço de exportação) inferior ao praticado em seu mercado de origem (valor normal). A diferenciação de preços em si já é considerada uma prática desleal de comércio.

Para determinação do dumping, deve-se auferir primeiramente o preço de exportação. Para isso, pode-se utilizar o preço de cada importação ou o preço médio do período analisado. A princípio, este preço deve ser o ex fabrica (isto é, sem imposto) e a vista. O preço ainda pode ser formulado ou construído, caso o efetivo não mereça confiança ou em caso de o importador e o exportador serem pessoas vinculadas pela revenda a terceiro independente ou por outro critério adequado. No caso de impossibilidade na investigação de todos os produtores e exportadores, a investigação pode se dar com base em amostragens, como ocorreu no caso "Estados Unidos - Medidas antidumping sobre produtos de aço a quente originários do Japão."41

Em seguida se determina o preço do produto similar ${ }^{42}$ no país exportador, ou valor normal. Este valor normal também é, em princípio, um preço ex fabrica e à vista, sendo o praticado no mercado interno do país exportador, devendo ter um volume significativo $^{43}$ e estar normalmente no comércio, ou seja, vendidos a compradores independentes ${ }^{44}$ e com aferição de lucro. Nos casos em que não existam produtos similares ou idênticos, ou caso a quantidade de exportações deste similar não tenha um volume significativo, deve-se proceder tomando o preço de exportação do mesmo produto pelo exportador para terceiro país ou tomar os custos de produção acrescidos do lucro. Dentre estes dois últimos critérios, o mais usado é o último, entretanto não há parâmetro de preferência ou hierarquia entre eles. No caso dos cadeados originários da China, a alegação de dumping baseou-se na comparação dos custos de produção da indústria peticionária acrescidos de uma margem de dumping de $15 \%$, com os preços de exportação das

\footnotetext{
${ }^{41} \mathrm{WT} / \mathrm{DS} 184 / \mathrm{R}$.

${ }^{42}$ Um produto é considerado similar a outro quando é idêntico àquele ou, na ausência deste produto idêntico, seja comparado a outro que apresente características suficientemente semelhantes, ressalte-se que aqui não cabe a substitutividade.

${ }^{43}$ Considera-se como volume significativo vendas no mercado interno do país exportador que representem pelo menos $5 \%$ do volume exportado para o Brasil.

${ }^{44}$ Este critério é utilizado na tentativa de se garantir que o valor normal não seja influenciado pela vinculação entre empresas.
} 
empresas acusadas para o Brasil. ${ }^{45}$ Já no caso ímãs de ferrite em forma de anel, por se tratar do envolvimento da República Popular da China que não é um país de economia predominantemente de escala, e por serem as partes as únicas produtoras do produto no mundo, utilizou-se os custos de produção das mesmas, obtidos por um questionário específico. $^{46}$

A seguir procede-se a comparação entre o preço de importação e o preço do produto similar no país exportador. A diferença entre esses preços é a chamada margem de dumping. Diferenças que afetem a comparação de preços, como características físicas, devem ser consideradas ou se possível eliminadas por meio de ajustes. Em vários casos analisados verifica-se a existência de argumentos desta ordem. No caso de investigação antidumping relativa ao cimento "portland" originário do México, o Governo da Guatemala não considerou as diferenças quanto aos volumes e níveis de comércio na confecção dos dados probatórios, o que os levou a serem penalisados. ${ }^{47}$

\section{c) A determinação de dano}

O Acordo trata também da determinação do dano ${ }^{48}$, o qual seria, juntamente com o nexo de causalidade, requisito necessário para que uma empresa seja condenada a reparar sua prática de dumping desleal. A determinação do dano a indústria nacional deve se basear em provas materiais, acrescida de um exame objetivo do volume das importações com dumping e o efeito nos preços dos produtos no mercado interno. Dano aqui deve ser entendido como dano material ou ameaça de dano material à indústria doméstica já estabelecida ou atraso no estabelecimento de uma indústria. A verificação do nexo causal também é necessária, devendo-se verificar se as importações afetadas pela prática do dumping são realmente responsáveis pelo dano causado à indústria doméstica, avaliando inclusive outros fatores que possam ser causa do dano na mesma ocasião.

\footnotetext{
${ }^{45}$ Processo no 10768.006634/94-84 (Confederação Nacional da Indústria).

${ }^{46}$ Processo $n^{\circ}$ MICT/SAA/CGSG 52100 - 000383/96 - 34 (Confederação Nacional da Indústria).

${ }^{47} \mathrm{WT} / \mathrm{DS} 60 / \mathrm{R}$.

${ }^{48}$ Este dano estaria diretamente ligado ao prejuízo à indústria doméstica representada pela totalidade dos produtos nacionais similares ao importado, ou pelo conjunto de produtores que fabriquem parcela significativa da mercadoria em análise.
} 
A ameaça de dano deve ser considerável, devendo estar baseada em fatores reais e não em meras alegações ou possibilidades remotas. Possíveis ameaças de dano devem ser previsíveis e iminentes. ${ }^{49}$ No caso envolvendo Guatemala e México, na investigação antidumping relativa ao cimento "portland", não havia evidências de dumping, dano e nexo causal para que se justificasse o início de uma investigação, visto que foi feita uma avaliação imparcial e objetiva, não trazendo subsídios de comprovação suficientes. Neste ponto feriu o artigo 2 do Acordo. ${ }^{50}$ Além deste caso, podemos mencionar o caso envolvendo México e Estados Unidos relativo ao xarope de milho de alta concentração, em que o painel decidiu pela inconsistência do laudo fornecido pelo México, o qual mencionava uma simples probabilidade de aumento substancial de importação como ameaça de dano. ${ }^{51}$

\section{d) Iniciativa e condução dos procedimentos investigatórios}

Tem legitimidade para dar início às investigações, a indústria nacional, suas autoridades $^{52}$ e ainda autoridades de um terceiro país interessado ${ }^{53}$. Para tanto, deve ser apresentada uma petição inicial demonstrando o dumping, o dano e o nexo causal entre as importações a preço de dumping e o dano. Se esta petição partir da indústria nacional, as autoridades deverão examiná-la, a fim de verifiquem a existência de motivos plausíveis para dar início à investigação e então notificar o Governo do respectivo exportador. ${ }^{54}$ No caso do cimento "portland", a Guatemala foi penalizada por não ter notificado o Governo mexicano a respeito do início da investigação. ${ }^{55}$

O texto completo da petição deverá ser fornecido aos exportadores conhecidos e às autoridades do membro exportador e caso se requeira ficará a disposição de outros interessados, levando-se em conta a confidencialidade de determinados documentos,

\footnotetext{
${ }^{49} \mathrm{O}$ Acordo prevê em seu artigo $3^{\mathrm{o}}$ quatro requisitos para que se comprove a ameaça de dano.

${ }^{50} \mathrm{WS} / \mathrm{DS} 60 / \mathrm{R}$.

${ }^{51} \mathrm{WS} / \mathrm{DS} 132 / \mathrm{R}$.

${ }^{52}$ Pode fazê-lo mesmo sem uma petição de sua indústria nacional, para tanto necessita ter comprovação da existência de dumping, nexo causal e dano. Vide art. $5^{\circ} \S 2^{\circ}$ do Acordo.

${ }^{53}$ Caberá ao governo do país importador aprovar esta petição para dar continuidade ou não ao processo. Vide art. 14 do Acordo.

${ }^{54}$ Há ainda a possibilidade de um representante das indústrias domésticas entrarem com o pedido como no caso das Fraldas Descartáveis, em que a investigação iniciou-se a pedido do Sindicato da Indústria de Perfumaria e Artigos de Toucador do Estado de São Paulo. Vide: processo $\mathrm{n}^{\mathrm{o}}$ 10768.030583/90-88 (Confederação Nacional da Indústria).

${ }^{55}$ WT/DS 60/R.
} 
conforme solicitação das partes. Nos casos em que se comprove a inexistência de dumping ou dano, a petição será rejeitada e a investigação será imediatamente encerrada. ${ }^{56}$

O prazo de duração das investigações deve ser de, no máximo, um ano. Em casos especiais pode exceder este prazo, mas que não ultrapasse dezoito meses. Na maioria dos casos, o prazo normal foi cumprido.

Nos casos em que haja vinculação entre produtor e exportador e em circunstâncias em que se trate de mercados localizados e integração regional, as regras são especiais para elas. Este dispositivo se refere desde uniões aduaneiras como o Mercosul até mercados comuns como a União Européia, onde prevalecem as regras dos acordos internos aos blocos.

\section{e) Provas}

No decorrer do processo de investigação, todas as partes interessadas ${ }^{57}$ podem produzir provas que sejam relevantes na forma escrita, tendo oportunidade de defender seus interesses. Informações adicionais poderão ser apresentadas oralmente, devendo também ser apresentadas por escrito e colocadas à disposição da outra parte. Deve-se ressaltar que quem entra com painel junto ao Órgão de Solução de Controvérsias da OMC obriga a outra parte a provar que as alegações contra ela não são reais, havendo, portanto, uma inversão do ônus da prova.

No início do processo de investigação, exportadores e produtores estrangeiros recebem um questionário, devendo ser respondido em até 30 dias, podendo este prazo ser prorrogado. As provas apresentadas ficam a disposição da outra parte, salvo os casos em que seja requerido confidencialidade.

\footnotetext{
${ }^{56}$ Ocorrerá nos casos em que se verifique que a margem de dumping é de minimis (inferior a $2 \%$ sobre o preço de exportação) ou que o volume das importações (menos de 3\% das importações do similar, a menos que o conjunto dos países atinja mais de 7\%) e o dano são desprezíveis.

${ }^{57}$ Entende-se como partes interessadas os exportadores ou produtores estrangeiros ou importadores do objeto sob investigação ou associações comerciais ou empresariais, com maioria dos membros exportador, produtor ou importador do produto em apreço, o Governo do Membro exportador e o produtor do similar nacional no Membro importador, ou associação comercial ou empresarial na qual a maioria dos membros produz o similar nacional. Esta lista não é exaustiva, podendo ser incluídas outras partes.
} 
No curso da investigação, as autoridades deverão verificar a autenticidade das informações sobre as quais basearão suas decisões. Investigações no território de outros membros podem ser realizadas para verificação de informações ou recolhimento de pormenores, desde que notifiquem a empresa envolvida e que tenha autorização do governo do Membro. ${ }^{58}$ No caso dos azulejos de porcelana envolvendo Argentina e Itália, a Argentina foi penalizada por ter desconsiderado a fonte primária para a coleta de informações, sem ter sequer justificado tal atitude. ${ }^{59}$

Se qualquer das partes negar acesso a informações ou atrasar desmotivadamente o fornecimento das mesmas, juízos preliminares e definitivos podem ser formados, com base nos fatos disponíveis, ou seja, no estado em que o processo se encontra. ${ }^{60}$ Antes de formular juízo definitivo, as partes devem ser informadas antecipadamente a respeito dos fatos essenciais sob julgamento para que possam defender seus interesses.

Em princípio, as autoridades determinarão margem de dumping individual para cada exportador ou produtor singular. Sendo isto impraticável, examinará um número razoável de partes interessadas ou produtos e formará amostragens estatísticas. Tal seleção se dará, preferencialmente após consulta aos envolvidos e obtenção de sua anuência. Nestes casos de restrição, previstas no parágrafo 11 do art. 6 , as autoridades deverão informar as margens individuais daqueles não incluídos na seleção, mas que venham a solicitá-la a tempo de se defenderem, a menos que o número seja grande e represente uma sobrecarga despropositada para as autoridades e impeça conclusões dentro dos prazos prescritos. ${ }^{61}$ No caso dos azulejos de porcelana originários da Itália, por exemplo, a Argentina foi penalizada por não ter utilizado uma margem de dumping individual e sim uma margem em comum. $^{62}$

\footnotetext{
${ }^{58}$ Anexo I do Acordo - Procedimentos para investigações in loco realizadas segundo o parágrafo $9^{\circ}$ do art. 6. ${ }^{59}$ WS/DS 189/R.

${ }^{60}$ Anexo II do Acordo - Melhor informação disponível no sentido do parágrafo 10 do art. $6^{\circ}$.

${ }^{61}$ No caso do aço envolvendo EUA e Japão, um dos argumentos do Japão era de que a exclusão de vendas domésticas seria um fator que estaria afetando a determinação do preço normal, aumentando a margem de dumping. E que o preço dos produtos vendido ao consumidor era mesmo mais caro que o vendido entre empresas, fato este não considerado pelos EUA na determinação do nexo causal. (WT/DS184/R).

${ }^{62}$ WS/DS $189 /$ R.
} 


\section{f) Medidas cautelares}

No decorrer da investigação de dumping, medidas provisórias podem ser adotadas antes do término do processo. Para isso, uma determinação, mesmo que preliminar de dumping e de conseqüente dano à indústria nacional já deve existir. $\mathrm{O}$ objetivo principal de tais medidas seria impedir danos durante o período em que se desenrola o processo, neste sentido, as autoridades devem julgar se realmente são necessárias.

As medidas provisórias ou cautelares podem ser aplicadas na forma de direito provisório ou garantia, igual ao montante do direito antidumping provisoriamente estimado, não podendo ultrapassar a margem de dumping estimada. Entre as duas formas, a segunda é mais aplicada. O prazo de aplicação das medidas deve ser o mais curto possível, não podendo se estender por mais de quatro meses, salvo em casos que por decisão das autoridades e a pedido, o mesmo se estenda por seis meses, ou em casos especiais em que este prazo deve ser de 6 a 9 meses. Para aplicação das medidas provisórias deve ser observado o disposto no artigo $9^{\circ}$ do Acordo. Verificou-se a aplicação de medidas provisórias no caso do cloreto de alumínio anidro ${ }^{63}$ pelo período de 5 meses e no caso dos ventiladores de mesa ${ }^{64}$ pelo período de 8 meses, sendo ambas aplicadas somente após a comprovação das queixas da peticionária. No caso do HFCS originário dos EUA, o painel decidiu pela não permissão de medidas provisórias além de 6 meses por entender que não estavam dentro da hipótese prevista no artigo 7.4, que dispõe a necessidade de uma imposição prolongada para extinguir o dano. ${ }^{65}$

\section{g) A solução da controvérsia por acordo de compromisso de preços}

Caso as partes litigantes queiram encerrar o processo antecipadamente, elas podem optar por fazerem um compromisso de preços. Para isso, o exportador assume o compromisso de rever seus preços ou cessar a exportação a preço de dumping fazendo cessar o efeito danoso causado a indústria doméstica. A existência do dumping e do dano deve ser preliminar à aceitação ou pleito de tais compromissos. No caso do leite, por

\footnotetext{
${ }^{63}$ Processo no 10768.016670/91-21 (Confederação Nacional da Indústria).

${ }^{64}$ Processo ${ }^{\circ} 10768.048207 / 93-29$ (Confederação Nacional da Indústria).

${ }^{65}$ WT/DS 132.
} 
exemplo, a investigação foi suspensa apenas em relação à Argentina e à Dinamarca pela aceitação de um compromisso de preços por ambas as partes. ${ }^{66}$

Caso as autoridades do país importador avaliem que tais compromissos não surtiram os efeitos esperados, elas não precisam aceitá-los. Para tanto, devem fornecer razões plausíveis a fim de que o exportador estabeleça comentários. O exportador também não é obrigado a concordar com sugestões de compromissos de preço provenientes das autoridades do membro importador.

As investigações podem continuar mesmo que se aceite um compromisso de preço caso o exportador deseje e as autoridades concordem. Contudo, se o resultado final for negativo quanto à existência do dumping e do dano, o compromisso é extinto, em caso positivo será mantido.

Em caso de violação do compromisso, as autoridades podem tomar medidas como aplicação de medidas provisórias, baseadas nas informações disponíveis, ou até mesmo, aplicar direitos antidumping definitivos em alguns casos.

\section{h) A imposição e cobrança de direitos antidumping}

Ao final do processo, pode ser definida a aplicação de direitos antidumping. Tratase da imposição de taxas às importações ocorridas a preço de dumping, tendo por objetivo neutralizar os efeitos danosos à indústria doméstica. Caberá às autoridades do membro importador decidir a respeito da imposição ou não destes direito antidumping. O montante deste direito pode ser a totalidade da margem de dumping ou menos do que esse valor. ${ }^{67}$ No caso das importações de chapas de aço inoxidável envolvendo EUA e Coréia, os direitos antidumping continuaram sendo aplicados, pois não se tinha certeza de que haveria outra solução $^{68}$, desta forma percebe-se que a imposição da medida antidumping se daria quando da ausência de outra forma de remediação.

Em situações em que ocorra a limitação de exame prevista no $\S 12$ do artigo $6^{\circ}$ do Acordo Antidumping, os direitos aplicados aos excluídos do exame não poderão exceder a

\footnotetext{
${ }^{66}$ Processo no MICT/SAA/CGSG 52100 - 0000001/99-89 (Confederação Nacional da Indústria).

${ }^{67}$ Vide artigo $2^{\circ}$ do Acordo

${ }^{68}$ WT/DS 189.
} 
média ponderada da margem de dumping estabelecida para os incluídos no exame e a diferença entre a média ponderada do valor normal praticada pelos selecionados e os preços de exportação dos individualmente examinados, sempre que o direito for calculado de forma prospectiva sobre o valor normal ${ }^{69}$. Este foi o aplicado no caso Estados UnidosMedidas antidumping sobre produtos de aço a quente originários do Japão, em que pela impossibilidade de se investigar todos os produtores e exportadores utilizaram-se o método de amostragem, estendendo, posteriormente, o resultado aos demais. ${ }^{70}$

A cobrança do direito antidumping pode ser desconsiderada caso as importações do produto representem menos de três por cento do total das importações, ou caso as importações do país seja o equivalente a menos de sete por cento das importações do produto. Além disso, se a margem de dumping for inferior a dois por cento do preço das exportações, ela será considerada como de minimis, sendo, portanto, desprezível. Como no Caso do Leite $^{71}$, em que o governo brasileiro exclui a Austrália do referido processo, devido ao fato de suas exportações estarem abaixo do valor de minimis, de acordo com o art. 14 do Decreto 1602 de 1995.

Existe a possibilidade de imposição de direitos antidumping de forma retroativa, sendo que para a determinação do valor deste direito, o montante deve ser estabelecido no prazo de 12 a 18 meses, após a data da formulação da petição para a fixação deste. Reembolsos deverão ser efetuados em prazo de até 90 dias após a determinação do valor. Excedendo este prazo, autoridades deverão prestar esclarecimentos, caso solicitado. No caso das fraldas descartáveis, o processo foi encerrado por reembolso por parte do governo argentino, a título de devolução de tributos internos. ${ }^{72}$ Caso o valor seja estabelecido de forma prospectiva, haverá medidas preventivas para serem utilizadas em caso de ser necessário reembolso imediato de direitos cobrados em excesso.

\footnotetext{
${ }^{69}$ Vide art. $6^{\mathrm{o}}, \S 10$ e art. $6^{\mathrm{o}}, \S 13 \mathrm{~b}$ do Acordo.

${ }^{70} \mathrm{WT} / \mathrm{DS} 184 / \mathrm{R}$.

${ }^{71}$ Processo $n^{\circ}$ MICT/SAA/CGSG 52100 - 0000001/99-89 (Confederação Nacional da Indústria).

${ }^{72}$ Processo n ${ }^{\circ} 10768.030583 / 90-88$ (Confederação Nacional da Indústria).
} 


\section{i) Países - membros em Desenvolvimento}

No artigo quinze do Acordo Antidumping, existe uma disposição de que os membros em desenvolvimento deverão ter atenção especial na aplicação de medidas antidumping, deve-se dar prioridade a soluções construtivas em detrimento à aplicação de direitos antidumping. $\mathrm{O}$ enunciado deste artigo pode ser considerado bastante esparso e vago, uma vez que têm um caráter mais sugestivo do que coativo. No caso das importações de roupa de cama de algodão proveniente da Índia, a União Européia foi penalizada por não explorar as possibilidades de medidas alternativas à aplicação dos direitos antidumping, violando o disposto neste artigo. ${ }^{73}$

\section{Considerações finais}

Estamos na era da globalização, que tem por conseqüência o crescimento da concorrência, seja esta leal ou desleal. O dumping é considerado uma prática comercial desleal, sendo o tratado antidumping uma alternativa na defesa contra competições desleais no mercado internacional.

Apesar de existir desde o início do século, o tratamento jurídico do dumping ainda é assombrado por dúvidas e problemáticas. Com a entrada em vigor, a partir de $1^{\circ}$ de janeiro de 1995, da Organização Mundial do Comércio - OMC, toma impulso o estudo das ações antidumping no mundo e suas técnicas de controle.

O comércio internacional de nossos dias apresenta um panorama complexo e cresce a um ritmo maior do que o das economias internas. O Órgão de Solução de Controvérsias tem lugar importante neste contexto, pois desempenha um papel fundamental na composição dos conflitos entre os países-membro da OMC, inclusive em casos referentes aos direitos antidumping. Além disso, temos a perspectiva de que sendo a disciplina jurídica que regula as ações antidumping nova, as disputas levadas até o OSC trarão um aprimoramento desta legislação que passará a enfrentar novas realidades.

Também é importante notarmos que na edição de medidas de ordem administrativa e judicial que busquem reduzir os efeitos das práticas desleais deverão ser observados os

\footnotetext{
${ }^{73}$ WT/DS 141/R.
} 
princípios do GATT/OMC e a regulamentação do direito nacional. Sendo que ambos devem estar em sintonia com a finalidade última de promover o crescimento do comércio internacional em uma economia cada vez mais globalizada.

Diante deste cenário, em que se percebe que a globalização não é uma opção neoliberal e facultativa e sim uma imposição de eficiência para o alcance de objetivos indispensáveis aos países em desenvolvimento como a aceleração da taxa de crescimento e a atualização tecnológica, podemos compreender o impacto econômico decorrente da aplicação de medidas antidumping e a relevância do fenômeno dumping dentro do contexto regulado pelo Direito Internacional Econômico.

Por fim, podemos dizer que a melhor conclusão que podemos chegar é a de que a legislação antidumping não pode ser desprezada nem substituída por outra. Isto acarretaria muitos problemas entre os países comerciantes, sendo melhor prosseguir com uma reformulação e modernização de alguns conceitos dentro da legislação. Só assim, ela seria capaz de combater o dumping realmente nocivo, sem ser objeto do interesse de países protecionistas. Talvez o conceito mais importante para que se alcance o objetivo final da legislação que seria a proteção dos produtores e dos consumidores, seja o de interesse público. Todavia, para isso, uma ação coletiva se faz necessária na busca pela revisão e inserção de novos elementos na legislação hoje utilizada.

\section{Referências}

1. BALASSA, Bela. The Tokyo Round negociation and the developing countries. Unctad, 1979.

2. BARRAL, Welber. Dumping e comércio internacional: a regulamentação antidumping após a Rodada Uruguai. Rio de Janeiro: Forense, 2000.

3. BARRAL, Welber (org.); OLIVEIRA, Odete Maria de (col.) [et. al] O Brasil e a OMC: os interesses brasileiros e as futuras negociações multilaterais. Florianópolis: Diploma Legal, 2000.

4. BARROS, Maria Carolina Mendonça de. Antidumping e protecionismo. São Paulo: Aduaneiras, 2003. 
5. BRAGWATI, Robert E. Hudec (ed.) Fair trade and harmonization: prerequisites for free trade? Cambridge: The MIT Press. 1997.

6. GOMES, Eduardo Biacchi. Blocos econômicos e solução de controvérsias. Curitiba: Juruá, 2001.

7. GOYOS JUNIOR, Durval de Noronha [et al.] Tratado de defesa comercial: antidumping, compensatórias e salvaguardas. São Paulo: Observador Legal, 2003.

8. GUEDES, Josefina Maria M. M. Anti-dumping, subsídios e medidas compensatórias. 3 ed. São Paulo: Aduaneiras, 2002.

9. HOEKMAN, Bernard M.; KOSTECKI, Michel M. The political economy of the world trading system: the WTO and beyond. 2 ed. Oxford University Press, 2001.

10. HOEKMAN, Bernard; MATTOO, Aaditya; ENGLISH, Philip (ed.) Development, trade, and the WTO: a handbook.. Washington: BIRD,2002.

11. JACKSON, John H. The Jurisprudence of GATT and the WTO: insights on treaty law and economic relations. Cambridge: University Press, 2002.

12. JOHANNPETER, Guilherme Chagas Gerdau. Antidumping: prática desleal no comércio internacional. Porto Alegre: Livraria do Advogado, 1996.

13. KRUEGER, Anne O. (ed.) The WTO as na international organization. The University of Chicago Press, 2000.

14. LAFER, Celso._A OMC e a regulamentação do comércio internacional: uma visão brasileira._Porto Alegre: Livraria do Advogado, 1998.

15. Direito e comércio internacional. São Paulo: LTr, 1994.

16. LONG, Olivier. Law and its limitations in the Gatt multilateral systems. G\&T/Martinus Nijhoff, Holanda, 1987.

17. MARQUES, Frederico do Valle Magalhães. O "Dumping” na Organização Mundial do Comércio e no Direito Brasileiro - Decreto n. 1.602/95. In: CASELLA, Paulo Borba; MERCADANTE, Araminta de Azevedo. (coord.) Guerra comercial ou integração mundial pelo comércio?: a OMC e o Brasil. São Paulo: LTr, 1998.

18. PEREIRA, Ana Cristina Paulo (org.) Direito internacional do comércio: mecanismos de solução de controvérsias e casos concretos na OMC. Rio de Janeiro: Ed. Lúmen Júris, 2003. 
19. PRAZERES, Tatiana Lacerda. Comércio internacional e protecionismo: as barreiras técnicas na OMC. São Paulo: Aduaneiras, 2003.

20. RATTI, Bruno. Comércio internacional e câmbio. 10. Ed. São Paulo: Aduaneiras, 2001.

21. SILVEIRA, Paulo Antônio Caliendo Velloso da. Defesa da concorrência no Mercosul: acordos entre empresas, abuso de posição dominante e concentrações. São Paulo: LTr, 1998.

22. THORSTENSEN, Vera. OMC - Organização Mundial do Comércio: as regras do comércio internacional e a nova rodada de negociações multilaterais. São Paulo: Aduaneiras, 2001.

23. Organização Mundial do Comércio: as regras do comércio internacional e a Rodada do Milênio. São Paulo: Aduaneiras, 1999. TREBILCOCK, M. J.; HOWSE, Robert. The regulation of international trade. 2 ed. Routledge: London, 2001.

24. VAZ, Isabel. Direito econômico da concorrência. Rio de Janeiro: Forense, 1993. 